\title{
Changes in Painting Style by Poststroke Mania
}

\author{
Eunjoo Rhee, Connie Hong, Young Eun Kim, Byung-Chul Lee \\ Department of Neurology, Hallym University Sacred Heart Hospital, Hallym University College of Medicine, Anyang, Korea
}

\section{Dear Sir:}

Post stroke neuropsychiatric syndrome is common. ${ }^{1}$ Many patients after stroke experience depression, cognitive impairment, personality change, psychosis, apathy, and anxiety. Mania can also be a consequence of stroke but is not common. ${ }^{2}$

"Mania" is described as a distinct period of abnormally and persistently elevated, expansive, or irritable mood, lasting at least 1 week in the Diagnostic and Statistical Manual of Mental Disorder-V. ${ }^{3}$ Mania seems to be observed more frequently with the right side brain lesions. ${ }^{4}$

Here, we report a professional artist whose painting style dramatically changed with manic illness from a recent stroke. Informed consent for this report was obtained.

A 58-year-old Korean man who had worked in Russia as a professional painter visited the emergency room due to a sudden onset of dysarthria and left side weakness, which were noted when he woke up in the morning. He did not have any other vascular risk factors except for smoking. On neurologic examination, dysarthria, left facial palsy and left hemiparesis (motor grade IV/IV) were observed. Left side sensory change and sensory extinction were noted, but prosopagnosia was not observed. With ophthalmologic examination, corrected visual acuity was $0.8 / 0.8$ on near card test, visual field defect was not observed on manual test and achromatognosia was not noted.

The brain magnetic resonance imaging revealed a territorial ischemic lesion with proximal occlusion of the inferior division of the right middle cerebral artery (Figure 1A). Cardioembolic source was not found on the transthoracic echocardiogram, transesophageal echocardiogram and holter monitoring. An antiplatelet drug and statin were prescribed.

When he visited our outpatient clinic 2 weeks after the symp- tom onset, although his neurological deficits were much improved, he became very erratic, aggressive, talkative, hyperenergetic, and lost the desire to sleep with an increased goal directed activities such as staying up all night and continuously drawing art pieces consisting of a human face. Furthermore, his wife noted that his style of painting was absolutely transformed. We compared the paintings he drew after his stroke with some of his paintings from Russia on his website before the stroke (Figure 1B, C).

His previous artwork showed complementary and subtle color schemes, with well-defined heads and figures using sharp lines. The paintings were ordered with an austere simplicity. On the other hands, his new artwork showed a drastic change in the artistic style. The drawings are complex, disrupted and disorganized with splattering of words and phrases (in more than one language). Use of color became broader and more overt.

After starting carbamazepine $100 \mathrm{mg}$ twice daily as a mood stabilizer, his mood slightly improved; however, he was still talkative, and his paintings were still awkward, complex and disorganized.

Here, we reported the case of a professional painter who showed changes in his artistic style and behavior after an ischemic stroke. There have been several case reports that showed how stroke influenced professional artists. ${ }^{5,6}$ However, mood change after stroke was not essential for a change in the artistic style. Particularly, some painters had difficulty painting landscapes and large figures because the right-hemisphere stroke commonly results in visuospatial neglect. ${ }^{5}$ In our case, we do not know exactly whether the change in his artistic style was caused by the poststroke mania or the stoke lesion itself affecting his creativity or executive function. Nevertheless, an intriguing point of this case is that his mood was clearly reflected 

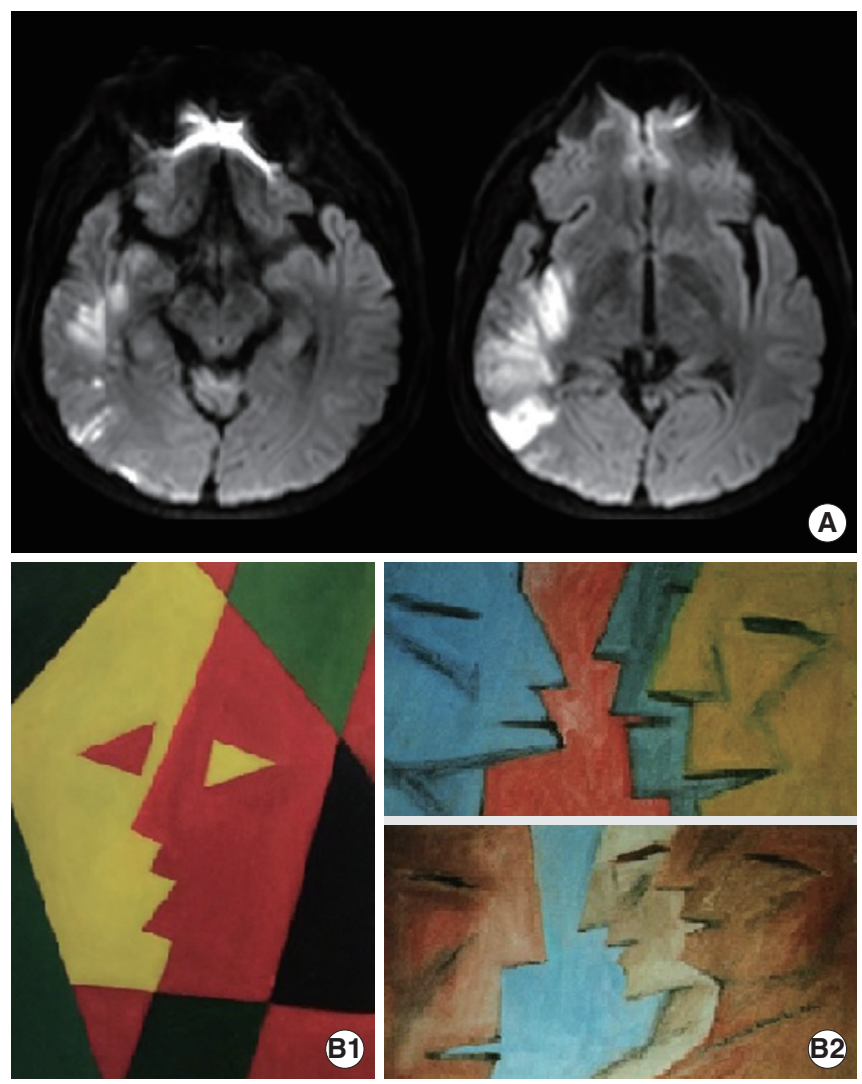

in his artistic work, although his neurologic deficit was minimal. In his work sentences written in Korean or Chinese characters may denote an expressive form of pressured speech in mania. Therefore, it could be postulated that his transformed artistic pattern is due to his affective problem.

The clinical profile of mania after stroke is similar to that of primary mania. The majority of stroke patients (92\%) present elevated mood as the first symptom followed by an increased rate or amount of speech (71\%), reduction of sleep (69\%), and agitation $(63 \%) .{ }^{4}$ In this case, the mood of the painter was similar to primary mania, even though he did not have any prior psychiatric illness nor family history. A previous functional imaging study found significantly reduced functional activity in the ventrolateral prefrontal cortex and amygdala in mania patients. Likewise, poststroke mania may be related to dysfunction in the ventral limbic pathway. ${ }^{7}$ In this case, the MRI findings showed the involvement of the inferior temporal lobe including the amygdala. Dysregulation of this pathway may explain the alteration in his mood, and the subsequent change in painting style in this patient. Moreover frontotemporal lesion can cause disinhibition of parietal lobe, and the disinhibition can be a cause of secondary mania as a result. Although the unexpected color and visual pattern in the previous work might reflect his artistic style like cubism, the color and visual pattern like the faces changed in his work after
Figure 1. (A) Brain MRI. Diffusion weighted image shows restriction in the right inferotemporal lobe including the amygdala. (B) The painting style before the stroke. The works are complementary and show subtle color schemes, with well-defined heads and figures using sharp lines; B1 drawn in 2009, B2 in 2012. (C) New art work after the right inferotemporal lobe infarction courtesy of the patient himself.

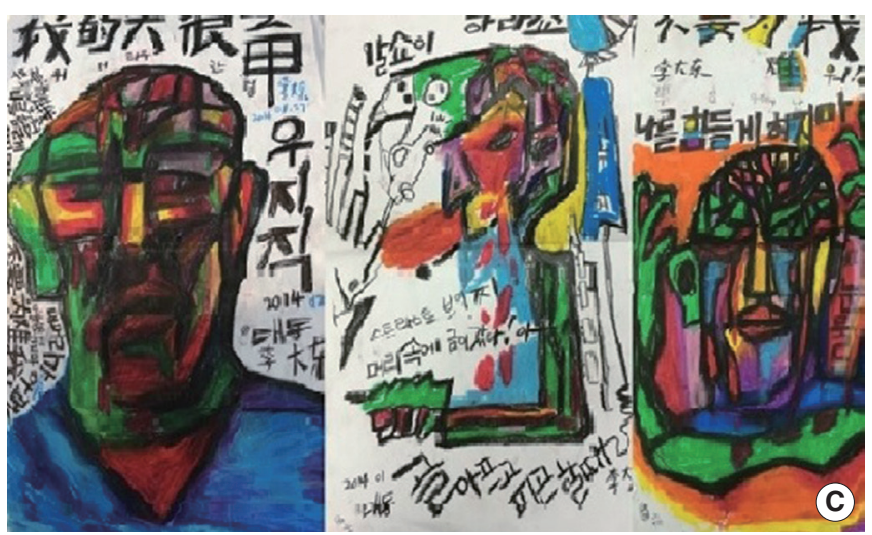

the stroke. The contribution of the inferolateral temporal cortex to the recognition of color and visual patterns should be considered.

\section{Acknowledgements}

We thank the patient described for allowing us to share his medical details and paintings.

\section{References}

1. Hackett ML, Kohler S, O’Brien JT, Mead GE. Neuropsychiatric outcomes of stroke. Lancet Neurol 2014;13:525-534.

2. Koreki A, Takahata K, Tabuchi H, Kato M. Increased left anterior insular and inferior prefrontal activity in post-stroke mania. BMC Neurol 2012;12:68.

3. Cosgrove VE, Suppes T. Informing DSM-5: biological boundaries between bipolar I disorder, schizoaffective disorder, and schizophrenia. BMC Med 2013;11:127.

4. Santos CO, Caeiro L, Ferro JM, Figueira ML. Mania and stroke: a systematic review. Cerebrovasc Dis 2011;32:11-21.

5. Bazner H, Hennerici MG. Painting after right-hemisphere stroke - case studies of professional artists. Front Neurol Neurosci 2007;22:1-13.

6. Annoni JM, Devuyst G, Carota A, Bruggimann L, Bogousslavsky 
J. Changes in artistic style after minor posterior stroke. J Neurol Neurosurg Psychiatry 2005; 76:797-803.

7. Strakowski SM, Eliassen JC, Lamy M, Cerullo MA, Allendorfer JB, Madore M, et al. Functional magnetic resonance imaging brain activation in bipolar mania: evidence for disruption of the ventrolateral prefrontal-amygdala emotional pathway. Biol Psychiatry 2011;69:381-388.
Correspondence: Byung-Chul Lee

Department of Neurology, Hallym University Sacred Heart Hospital, Hallym University College of Medicine, 22 Gwanpyeong-ro 17beon-gil, Dongan-gu, Anyang 14068, Korea

Tel: +82-31-380-3740, Fax: +82-31-380-4659

E-mail: ssbrain@hallym.ac.kr

Received: August 13, 2015

Revised: September 21, 2015

Accepted: October 17, 2015

The authors declare that they have no financial or other conflicts of interest in relation to this research and its publication. 